\title{
Políticas educacionais neoliberais na educação básica da rede pública de Goiás
}

\author{
LIBÂNEO, José Carlos; FREITAS, Raquel A. Marra da \\ Madeira (Orgs.). Políticas educacionais neoliberais e \\ escola pública: uma qualidade restrita de educação esco- \\ lar. Goiânia: Editora Espaço Acadêmico, 2018, 364p.
}

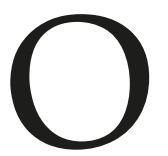

rganizado por José Carlos Libâneo e Raquel A. M. da Madeira Freitas, o livro Políticas educacionais neoliberais e escola pública: uma qualidade restrita de educação escolar reúne resultados de investigações do Grupo de Pesquisa Teorias da Educação e Processos Pedagógicos, vinculado ao Programa de Pós-Graduação em Educação da Pontifícia Universidade Católica de Goiás.

Entre as muitas contribuições que a obra põe à disposição do leitor, talvez a mais importante seja a do sentido que a escola pública precisa ter nos dias que correm. Se, de um lado, os autores cumprem a tarefa de expor cristalinamente as articulações entre os projetos internacionais de educação e a escolarização nacional - concretizada no Pacto pela Educação em Goiás, em 2011 -, de outro, oferecem elementos teóricos e políticos no âmbito do materialismo histórico para enfrentarmos o avanço do ideário burguês sobre a escola pública. Dividido em duas partes, na primeira, Políticas educacionais, critérios de qualidade de ensino e repercussões nas práticas pedagógicas, com oito capítulos, elucida as políticas neoliberais e suas repercussões na educação básica. Discute como as políticas educacionais adotam critérios de qualidade de ensino pautados em resultados quantitativos e seus desdobramentos nas práticas pedagógicas de professores e gestores das escolas públicas de Goiás. Na segunda parte, Políticas educacionais internacionais e repercussões na organização escolar, na formação de professores e no trabalho docente, com cinco capítulos, expõe o exame da materialização das diretrizes de organizações internacionais na educação pública e o movimento de internacionalização que a atinge associado à crescente precarização dos processos educativos. Consta entre eles as avaliações em larga escala, a gestão orientada por organizações sociais e os programas de educação integral, a exemplo do Mais Educação.

Olivro resulta de uma pesquisa "guarda-chuva", Políticas educacionais oficiais: estudo das repercussões de seus referenciais de qualidade de ensino nas práticas pedagógicas e na aprendizagem dos alunos em escolas públicas estaduais de ensino fundamental, cujo campo de estudos, entre 2014 e 2016, foram escolas públicas de educação básica que apresentavam maiores e menores notas no Ideb. Com base na concepção materialista histórico-dialética, 
desenvolveram-se pesquisas documental, bibliográfica e de campo, objetivando compreender as "influências nos objetivos, formas de funcionamento das escolas e práticas pedagógicas, de políticas educacionais formuladas com base em orientações de organismos internacionais" (p. 22), informações oferecidas ao leitor no Capítulo 1.

No Capítulo 2, Políticas educacionais neoliberais e escola: uma qualidade de educação restrita e restritiva, Libâneo argumenta que o neoliberalismo, ideologia do capital fundamentado nas teorias gerenciais de qualidade, procura impor à sociedade os princípios da eficiência, competitividade e produtividade. Demonstra como as políticas educacionais no Brasil incorporam orientações de organismos internacionais - Banco Mundial (Bird), Banco Interamericano de Desenvolvimento (BID), Fundo Monetário Internacional (FMI), Organização para a Cooperação e o Desenvolvimento Econômico (OCDE), Organização das Nações Unidas para a Educação, a Ciência e a Cultura (Unesco) -, ressaltando a lógica da "governança empresarial". O autor evidencia que a finalidade educativa da escola, "formação de trabalhadores para as necessidades imediatas da economia" (p. 47), atrela-se a critérios gerenciais de qualidade do mercado: eficiência, competitividade e produtividade. Deles derivam um currículo escolar instrumental, pragmático, visando a empregabilidade, ademais de legitimado pelo sistema de avaliação em larga escala, assentado no desempenho individual, bem como no trabalho do professor. Trata-se da "responsabilização da escola e dos professores pelo êxito ou insucesso dos alunos" (p. 54). Fica patente que a qualidade da educação, social e historicamente construída, liga-se ao projeto societário burguês. O autor defende a possibilidade de uma "qualidade de educação centrada no desenvolvimento humano para uma sociedade justa e democrática" (p. 57), assentada nos princípios da teoria histórico-cultural, perspectiva que percorre todos os capítulos.

No Capítulo 3, Freitas, Libâneo e Eliane Silva discutem as Políticas educacionais baseadas em resultados e seu impacto na qualidade do ensino: a visão de professores e gestores sobre a reforma educacional no estado de Goiás. Implementada em 2011, seus aspectos quantitativos afetaram o sistema escolar e o trabalho pedagógico orientados por resultados. As avaliações de desempenho delinearam um "currículo mínimo" - a leitura e a escrita, a expressão oral, o cálculo, a solução de problemas -, orientado por conteúdos básicos de aprendizagem, baseado em habilidades, valores e atitudes requeridos pelo mercado. Gestores e professores entrevistados assinalaram que a reforma do ensino não prepara os alunos para a empregabilidade, para o mundo do trabalho ou para o ingresso no ensino superior. Sua estratégias, como "Currículo Referência, bimestralização, avaliações externas à escola, descritores, livro didático, entre outros" (p. 95), "têm foco organizacional". Constituídos em instrumentos de controle docente, reduz-se "a treino, repetição de exercícios, preparação para avaliações externas" (95). A maioria dos gestores e professores entrevistados têm "posição contrária às finalidades educativas, ações e estratégias da Seduce, com uma crítica contundente aos seus impactos negativos na aprendizagem dos alunos" (p. 97), 
pois perceberam que mecanismos de avaliação em larga escala corroboram a competição entre escolas, destacando os "melhores" gestores, bem como inviabilizando a autonomia do professor", tornando-o semelhante a "um gerente" (p. 111). Nessa esteira, é possível pensar o trabalho docente e os sistemas de bonificação e premiação que materializam o "[...] desmonte do plano de carreira dos professores [...]" (p. 118), instituindo a desvalorização profissional e a perda de autonomia, caso do Programa Reconhecer.

A Reforma educacional goiana: desdobramentos no currículo e nas práticas educativas é discutida no Capítulo 4 por Simônia Peres da Silva. Tematiza a relação entre as orientações de organismos internacionais e o Pacto pela Educação em Goiás, de 2011: escolas transformam-se em prestadoras de serviços educacionais, alunos e pais em consumidores, professor em insumo e aprendizagem em produto. O Pacto, de concepção economicista, afeta o trabalho docente, o currículo e a sala de aula. No âmbito do trabalho docente, o Programa Reconhecer - substituto do Plano de Carreira - constitui-se em "um sistema de reconhecimento e remuneração por mérito" (p. 135), utilizado para controlar e punir professores, numa lógica de responsabilização e precarização, modificando sua identidade profissional tendo em vista transformá-lo em professor-tarefeiro. A perversidade sobre o professor é exemplificada por meio da análise do documento Frequência Social, que divulga "para a comunidade escolar a frequência dos professores e o número de aulas programadas/ministradas por eles" (p. 138). A organização curricular se referencia ao conteúdo das avaliações nacionais e regionais cuja meta é a preparação dos alunos para um bom desempenho nos exames. A sala de aula transforma-se em locus de ações fraudulentas: cria-se o Período de Intensificação da Aprendizagem (PIA), modelo no qual aulões de 1 hora e 40 minutos são ministrados durante quinze dias, no fim do semestre letivo, com o intuito de "melhorar o fluxo escolar", para aumentar o Ideb, bem como conter a evasão escolar via promoção automática de alunos. A escolarização subsume-se às necessidades do mercado e a qualidade confunde-se com rendimento.

Pessoni e Libâneo, no quinto Capítulo, refletem sobre Finalidades da educação escolar e critérios de qualidade de ensino: as percepções de dirigentes escolares e professores. Com base numa análise comparativa de documentos do Banco Mundial, Unesco e OCDE, do Pacto pela Educação e documentos próprios da escola, articulada às entrevistas com coordenadores pedagógicos, diretores e professores, concluem que no final do século XX e início do XXI produziram-se finalidades que submeteram a educação à "preparação das pessoas para o mercado de trabalho e para o individualismo" (p. 154). A partir da década de 1990, empreender, atenuar a pobreza, ajustar indivíduos e administrar contradições produzidas pelas desigualdades sociais são algumas das finalidades educativas ditadas pelo capital às escolas. As qualidades da escolarização seguem a lógica gerencial, utilizam critérios de aferição de rendimento e desempenho para produzir resultados passíveis de compor índices de desenvolvimento, demonstrando que "o conceito de qualidade baseado em resultados configura o modelo de gestão pública denominado 'qualidade total"' 
(p. 159). A estandardização de resultados assoma como "sucesso na aprendizagem" e produz modelos de excelência a serem seguidos - tornar-se referência é o mote das políticas educacionais em Goiás!

Os Capítulos 6, 7 e 8 desenvolvem análises relativas às áreas da Língua Portuguesa, Ciências e Matemática. Leão e Ribeiro, no Capítulo 6, tematizam o Impacto das políticas educacionais nas práticas pedagógicas de professores de Lingua Portuguesa. Sob a perspectiva vygotskyana, "de que o desenvolvimento do pensamento é determinado pela linguagem" (p. 177), defendem o seu ensino como primordial para o aprendizado nas demais áreas do conhecimento e problematizam o "fracasso" na interpretação de textos, na expressão das ideias e na escrita. Para as autoras, a qualidade do ensino de Língua Portuguesa não pode ser mensurada pelas avaliações de larga escala que se converteram em mecanismos de regulação. O professor treinador, para atingir notas satisfatórias nos índices de qualidade, usa as provas de anos anteriores como materiais didáticos. $\mathrm{O}$ texto insta o leitor a pensar sobre o ensino da Língua Portuguesa num contexto de transformações históricas, políticas, culturais e econômicas que redundaram numa reestruturação ou reorientação curricular da área com o intuito de reduzir as taxas de evasão e repetência escolares. A reforma da Língua Portuguesa, orientada por organismos internacionais, foi necessária para implementar a concepção de "aprendizagem ao longo da vida" (p. 191); para entender esse movimento, sugerem compreender os aportes da Linguística, Psicolinguística e Sociolinguística, bem como os estudos sobre alfabetização e ensino da língua materna - letramento.

Cunha, Oliveira e Melo, no sétimo Capítulo, analisam o Impacto das políticas educacionais nas práticas pedagógicas de professores de Ciências. Assinalam que o ensino de Ciências esteve historicamente articulado com o projeto societário norte-americano de educação para o desenvolvimento econômico, baseado na união entre ciência e tecnologia. Professores de Ciências entrevistados confessam que seu trabalho docente é limitado pelo ato de "fornecer um 'kit' de habilidades para sobrevivência social e empregabilidade" ( $p$. 209), o que nega o apregoado por documentos como Plano Nacional de Educação e Plano Estadual de Educação de Goiás. A lógica das avaliações de desempenho define o processo de ensino-aprendizagem e imprime a qualidade de educação pretendida pelos interesses do capital: qualidade mínima para garantir maiores condições de expropriação da força de trabalho.

O texto de Cunha, Borges e Melo finaliza a primeira parte e nele se discute os Impactos das políticas educacionais nas práticas pedagógicas de Matemática. Problematizam as políticas educacionais que seguem diretrizes de organismos internacionais, revertendo em uma reforma do ensino de Matemática vincada pela qualidade, eficiência e equidade. Orientada em grande medida pelo Movimento Matemática Moderna, definiu o que era necessário avaliar segundo as competências exigidas pelo mercado, resultando em uma estrutura curricular instrumental de conhecimentos básicos de aritmética para resolução 
de problemas domésticos e de trabalho. Os critérios de qualidade de ensino baseados na produtividade e competitividade são definidos pelo desempenho dos alunos nas avaliações externas, o que acaba por mensurar a "qualidade" do professor de Matemática e contribuir para a construção do senso comum de que essa é uma ciência muito dura e de compreensão árdua, logo, para poucos.

A segunda parte do livro inicia-se com o Capítulo 9, O professor e sua formação na perspectiva dos organismos multilaterais; nele, Iraci Silva e Beatriz Zanatta examinam as orientações do Banco Mundial para a formação docente. O objetivo foi garimpar indícios que interferem nas questões relativas à formação, ao trabalho docente e às concepções que incidem sobre a imagem social dos professores. Com uma ampla pesquisa documental e bibliográfica, demonstram o lugar estrategicamente ocupado pelo Banco no desenvolvimento da economia global, desde sua criação na década de 1940 até as posições políticas, pós-1980, que prescindiram do viés militar. Nesta virada de posição, começa a exportar políticas educacionais, estimulando reformas educacionais que superassem "a má formação docente", responsabilizada pela má qualidade da escola, e denunciando sindicatos docentes como entraves à concretização de seu projeto político. Concluem que a formação do professor sugerida pelo Banco e outros organismos internacionais é orientada para uma formação desintelectualizada e despolitizada.

Camargo e Rosa, no Capítulo 10, Internacionalização das políticas educacionais e precarização do ensino, discutem o trabalho como princípio ontológico e como atividade ontogenética que levou ao surgimento e desenvolvimento da humanidade e dos processos de humanização. A educação escolar e o acesso às formas mais elaboradas da consciência genérica - arte, ciência, filosofia, técnica, tecnologia - são propostas como histórica e humanamente necessárias. Sua crítica à internacionalização das políticas educacionais colocam-nas como responsáveis pela precarização do trabalho docente e do ensino escolar, visíveis nas narrativas de professores do ensino fundamental da rede de ensino do estado de Goiás.

No Capítulo 11, As implicações das avaliações em larga escala sobre a escola e o trabalho pedagógico, Santos, Vilalva e Ferreira explicitam os impactos das políticas de avaliação no trabalho pedagógico e na gestão escolar sob a vigência do Ideb como métrica da qualidade escolar. Os autores convergem sobre a construção de uma agenda internacional para a educação por parte de organismos internacionais focalizada na associação entre qualidade da educação, avaliações externas e atuação dos professores, cujos impactos sobre as escolas e o trabalho docente estão suficientemente esclarecidos.

No Capítulo 12, A gestão das escolas públicas por meio de organizações sociais em Goiás: a quem serve este projeto?, Anderi e Tiballi abordam as políticas sociais neoliberais na constituição das organizações sociais (OS) destinadas à gestão de escolas públicas no estado de Goiás. Surgidas no contexto de Reforma de Gestão Pública, nos anos de 1990, durante o Governo de Fernando Henrique Cardoso, são um dos instrumentos de privatização 
utilizados para substituir uma instituição pública por uma, particular. No projeto de Reforma de Educação em Goiás, de 2011, ao transferir a gestão pública da escola para OS justificaram-na com o argumento da elevação da avaliação do Ideb, assim como da responsabilização individual do professor pelo desempenho do aluno. As autoras denunciam a implementação do projeto de gestão por OS por não assegurarem aos estudantes o acesso ao conhecimento científico e cultural necessário ao seu desenvolvimento pleno.

Fabrício Cardoso da Silva, no Capítulo 13, Programa Mais Educação: educação integral como estratégia para a qualidade de ensino?, problematiza, com base nas práticas avaliativas de larga escala, na implementação do Plano Municipal de Educação, no projeto de educação integral, os referenciais para aferir a qualidade da educação. Ao estudar as orientações de organismos multilaterais, resultados de entrevistas com professores, gestores, monitores socioculturais que atuaram no Programa entre 2008 e 2014 constatou que a expansão do tempo escolar não foi capaz de romper com a operacionalização utilitária do currículo. Isso compromete os princípios clássicos da educação integral, pois estes programas incumbem a escola de sanar suas próprias deficiências de infraestrutura e colocam numa perspectiva ambígua sua capacidade de ofertar uma educação com qualidade social. Além disso, há uma responsabilização do fazer docente para garantir a permanência do aluno na instituição; por outro lado, retira do Estado seu dever precípuo de garantir uma educação com qualidade ao buscar parcerias privadas com instituições da sociedade civil.

Nas palavras de Libâneo e Madeira: "Nossa expectativa é de que este livro represente um marco na compreensão e discussão do impacto avassalador que as políticas educacionais, sob a égide do neoliberalismo e por meio da estratégia de internacionalização, estão provocando nas escolas e salas de aula, no trabalho dos professores, na atividade pedagógica e didática e no futuro destas e das próximas gerações de crianças e jovens, negando-lhe o direito ao desenvolvimento mais amplo por meio da educação escolar".

Certamente, a leitura dessa obra realizará a expectativa de seus organizadores. Mas não só. Ajudará a despertar a indignação em seus leitores e a subsidiar a luta - tão necessária nos dias que correm - em defesa da escola pública brasileira e de seu compromisso com a classe trabalhadora.

Recebido em: 10/12/2018 e Aprovado em: 17/12/2018

\section{Sobre as autoras:}

FERNANDA DE ARAGÃO MIKOLAICZYK 
Doutoranda no Programa de Pós-Graduação em Educação da Universidade Federal de Santa Catarina, na linha de pesquisa Trabalho, Educação e Política. Participa do Grupo de Investigação sobre Política Educacional (GIPE-Marx). Email: fernandamikolaiczyk@hotmail.com.

\section{LETÍCIA FIERA}

Professora da rede pública do Estado de Santa Catarina. Doutora em Sociologia Política pela Universidade Federal de Santa Catarina. Autora do livro Jornalismo econômico e os lobos das finanças: Grupo Folha e o Governo Lula. Participa do Grupo de Investigação sobre Política Educacional (GIPE-Marx). Email: leticia.fiera@gmail.com. 